\title{
Strength reanalysis and influence line equation of rack system drive force
}

\author{
Miroslav Blatnický ${ }^{1}$, Ján Dižo, ${ }^{1,}$, Mária Blatnická ${ }^{2}$ \\ ${ }^{1}$ Department of Transport and Handling Machines, Faculty of Mechanical Engineering, University of \\ Žilina, Univerzitná 1, 01026 Žilina, Slovak Republic \\ ${ }^{2}$ Department of Applied Mechanics, Faculty of Mechanical Engineering, University of Žilina, \\ Univerzitná 1, 01026 Žilina, Slovak Republic
}

\begin{abstract}
The paper deals with strength reanalysis of proposed rack system design. At previous analysis it was found out that the structure does not met the safety and reliability conditions due to exceeding allowable stress. After structure modification the next step will be determination of influence line equation for rack system drive force as its effect is time dependent in operation.
\end{abstract}

Keywords: Rack system, functional calculation, constructional design, stress analysis

\section{Introduction}

Generally, handling equipment consists of bearing construction, driving mechanism and other parts (various additional equipment, e.g. a cab). The steel construction forms a basic bearing part of any handling equipment. Mostly it means the bearing construction of all equipment working parts which transmits all external loads affecting the equipment. The shape of the steel construction defines its kind and purpose of use [1]. Its production is carried out by joining parts into larger constructions by means of either riveting (an older way), or welding (nowadays the most common way) [2-5]. For this reason, the designed steel construction of rack system (Fig. 1) will be constructed by welding. Among the most important customer's requirements we can include the safety of the construction. The steel construction should be light and rigid enough to ensure the economy of production and operation, it should also be aesthetic and take into account the perfect arrangement of the steel construction as a whole, it should allow a safe access to all mechanisms, and it should also have an appropriate division with regard to its assembly.

In designing the steel construction we consider particularly safety and consequently, reliability (summary of characteristics and factors which affect usability, no-failure operation, and maintenance of the steel construction) $[5,6]$. The construction will be formed by means of welding and we have to ensure the welding capability of material [7]. Welding steel without special requirements and welding conditions (due to the demand for

\footnotetext{
* Corresponding author: jan.dizo@,fstroj.uniza.sk

Reviewers: Tomasz Domański, Krzysztof Talaśka
} 
the economy of production) cannot contain more than $0.18 \%$ of carbon resulting in strength less than $400 \mathrm{MPa}$ of the given classes of steel used for the steel construction. To increase strength we can use steel with other alloyed element, for example steel 11523 has strength $520 \mathrm{MPa}$ and is alloyed by manganese (max: $1.5 \% \mathrm{Mn}, 0.55 \% \mathrm{Si}, 0.3 \% \mathrm{Cr}, 0.3$ $\%$ Ni). That's why we have chosen steel STN 11523 as basic material of rack system construction [8].

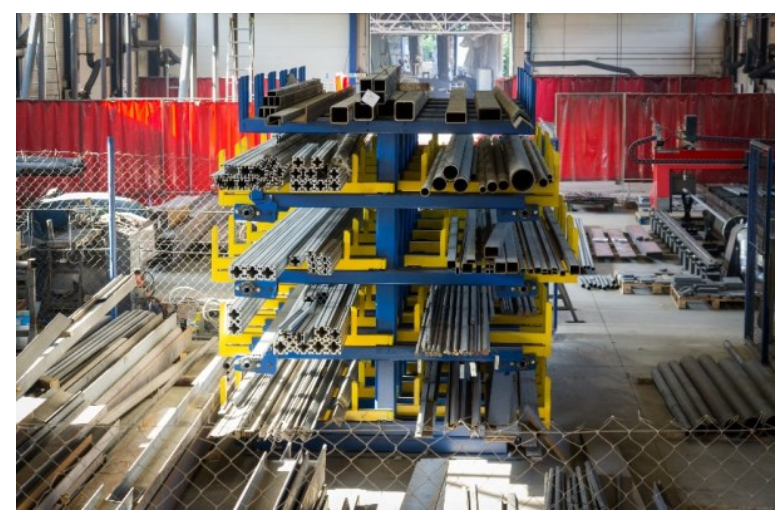

Fig. 1. Metallurgical material warehouse within a company

In welded constructions influenced statically and dynamically we use butt and fillet welds [9-11]. The calculation is run on dimension principles with certain specification. To save storage area, for the company it is important that the rack, serving for material storage, provides the storage in several layers in height. To alleviate handling with material stored in the rack and to increase clarity, one kind of material is deposited together if possible. Moreover, we have to take into account the principle that if we put more kinds of material into the rack, loading and unloading of material at the bottom is time-consuming. Therefore, to increase the handling efficiency it is advisable to construct storage racks as a mechanism with a single degree of freedom [12], which allows to pull out the material horizontally and to grip it by means of a grab bucket.

\section{Strength reanalysis of the rack system}

The strength analysis of the construction showed deficiencies of the design in the pulled-out position [13]. Analyses were carried out using FEM by means of Adina software [14-16]. That is why it is necessary to make some changes in the construction. One possible solution to this problem is to weld $10 \mathrm{~mm}$ thick sheet between the central and horizontal beams, and thus increase thickness. The geometry of bearing construction model is formed from three separated parts which are joined by means of interconnecting the displacements in each of the corresponding nodes of the mesh (Fig. 2).
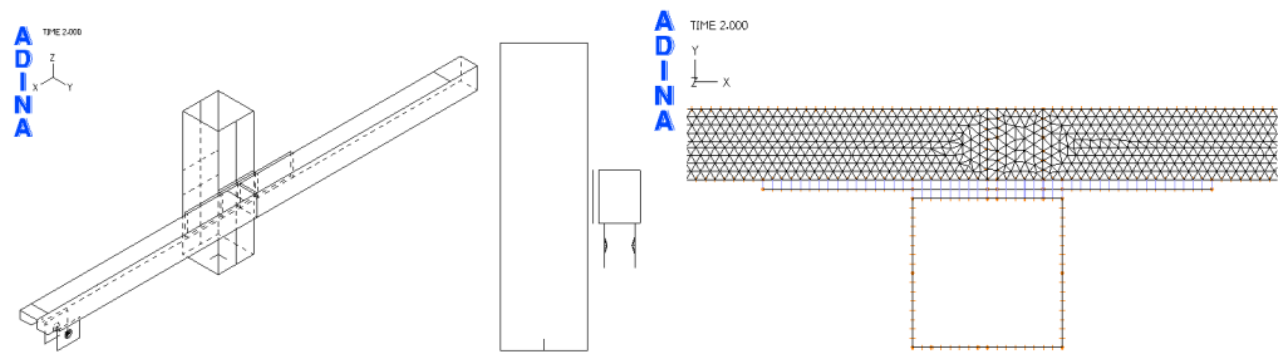

Fig. 2. Geometry of the bearing construction with the welded sheet (on the left) and connection of circuit nodes (on the right) 
We have decided for this method so that the model was more real. If only one mid-surface was modeled with the thickness of the corresponding amount of two beams and the sheet, the results would be less accurate because the sheet is welded to the beams only on the circuit and is not connected with the whole surface [17-19].

As it is seen in the Figure 3, such construction change can ensure a decrease of the stress in the beams from $195 \mathrm{MPa}$ to $118.6 \mathrm{MPa}$. By comparing the obtained stress value with the allowed stress of a weld for the material S355 (148 MPa) we conclude that after using this construction change, the maximum stress value will decrease to a safe value, and therefore the construction safely transmits the required load.

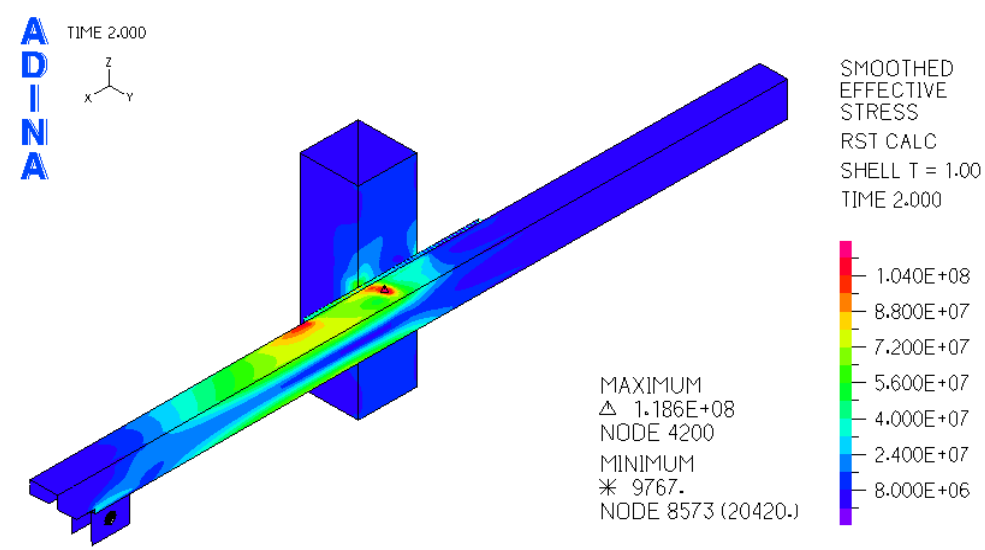

Fig. 3. Detail of stress in the construction after designed change

The strength analysis was carried out in parts. The pull-out rack analysis has proved that this part of the construction meet the safety requirements while loading the pull-out or pullin rack positions. The analysis of the bearing construction showed significant deficiencies in strength and stability of the pulled-out rack position when the welds had the stress 213.6 $\mathrm{MPa}$, and at the same time the arms are deformed. So the ends of the arms move by 4.18 $\mathrm{mm}$ with pulled-out length of $2095 \mathrm{~mm}$ (Fig. 4). That is why we carried out the change of the construction.

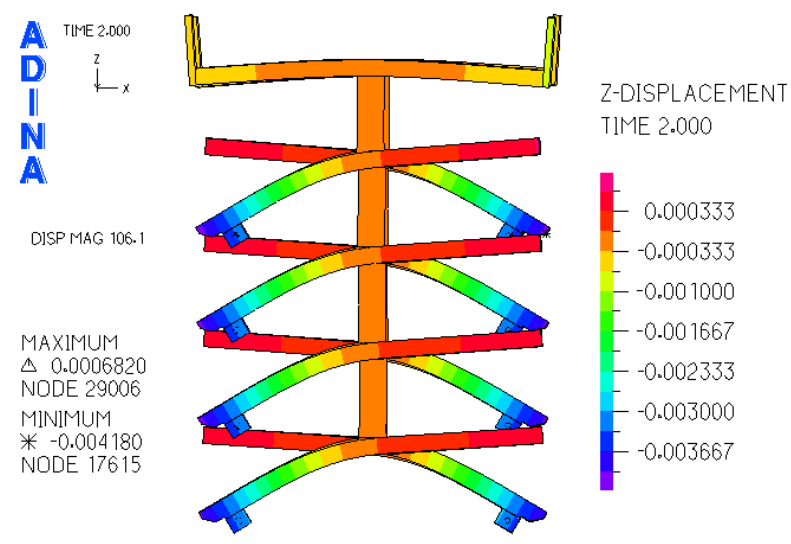

Fig. 4. Simulated displacements of the construction without the construction change in the vertical direction

The construction change included the weld between the central beam and horizontal beams and thus increase the thickness of the construction. This solution proved to be right 
as the stress values of welds went down to the value of 118.6 MPa. This value is acceptable and the construction meets safety requirements.

\section{Drive force influence line equation}

The static calculation [13] has a deficiency in the form of a large computational space if we want to determine the actual reaction forces values depending on the size of the rack extension. This is because of the burden loading the construction, and therefore the hand crank, is not static but movable [20]. In equations, there are many constant variables (the weight load is constant and their geometry does not change with respect to the rack when it is pulled out). Therefore, it will be appropriate to simplify the equation in such a way that we calculate all partial loads to obtain the resulting load and determine its position relative to the rack.
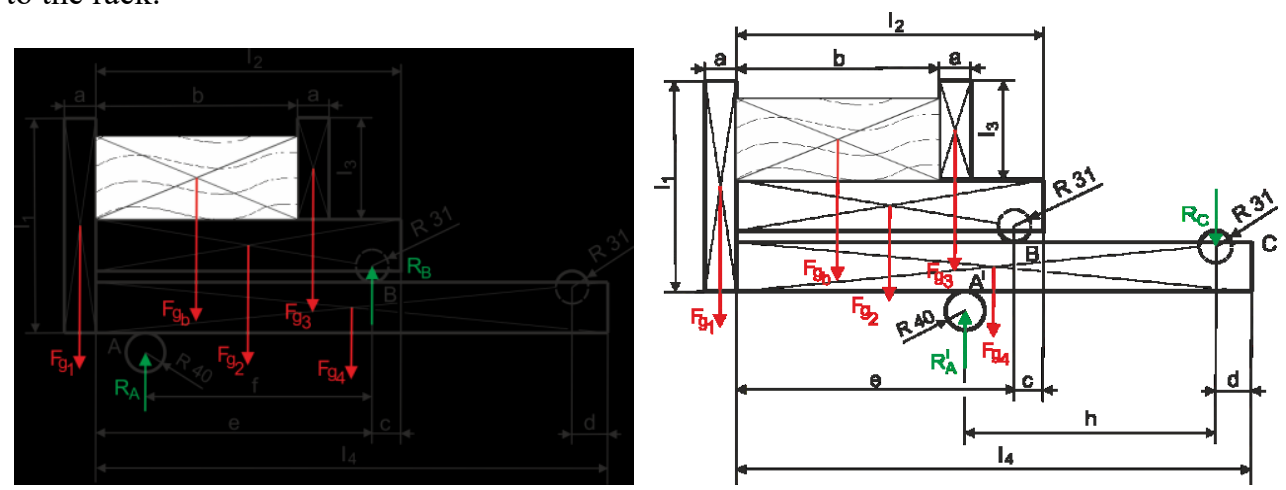

Fig. 5. Releasing of the mechanism for pulling out (on the left) and pulling in (on the right)

The horizontal coordinate of the centre of gravity $x_{C G}$ of the moving material (the loaded material and the weight of the movable part of the rack) from the left edge of the rack at the pull-in position is obtained from Fig. 5 on the left using a relation (1):

$$
x_{C G}=\frac{\frac{a}{2} \cdot F_{g 1}+F_{g b} \cdot\left(a+\frac{b}{2}\right)+F_{g 2} \cdot\left(a+\frac{l_{2}}{2}\right)+F_{g 3} \cdot(1.5 \cdot a+b)+F_{g 4} \cdot\left(a+\frac{l_{4}}{2}\right)}{F_{g 1}+F_{g 2}+F_{g 3}+F_{g 4}+F_{g b}} .
$$

By placing the appropriate values as variables in equation (1), we get the position of the centre of gravity of the total load $x_{C G}=515.42 \mathrm{~mm}$ from the left edge of the rack. From the equation denominator (1) for the total weight of the moving parts at the maximum load $m=3,000 \mathrm{~kg}$, we get $F g=5251.68 \mathrm{~N}$. Let us define the position of the resulting centre of gravity by the distance $z$ from bearing $B$ (see Figure 6 on the left).

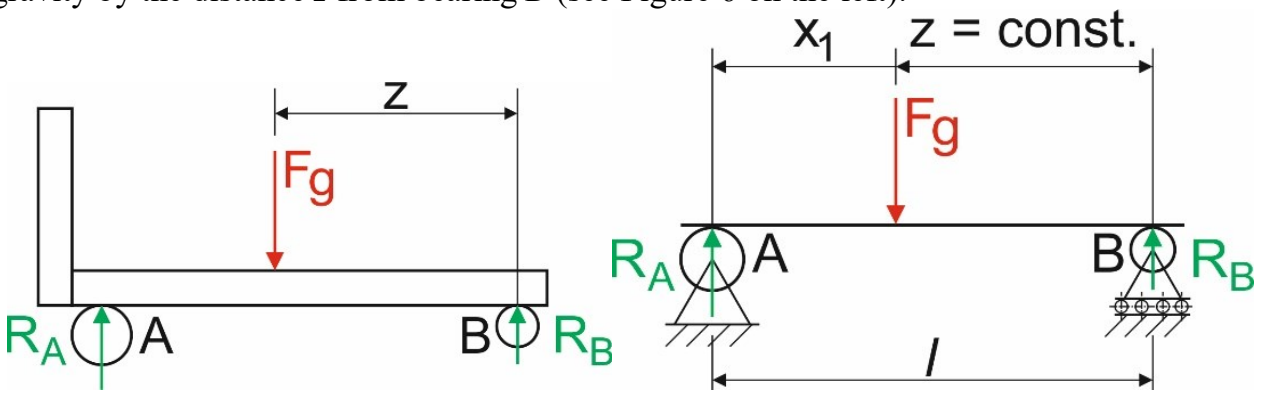


Fig. 6. Schematically depicted geometry of the pull-in position of the rack (left) and schematic representation of the rack considered as a plain beam (right)

In order to check the correctness of the solution, it is sufficient to make the calculation of equations [13], but using the total value $F g$ and its position, but at the same time it was necessary to create the equation (2) in such a way as to explain the variable $x_{1}$, i.e. ejecting the rack in the first boundary. This situation is documented in Fig. 6. right and the equation (2) derived from it:

$$
\sum M i_{B}=0, \quad \Rightarrow R_{A} \cdot\left(l-x_{1}\right)=F_{g} \cdot z
$$

From the equation (2) we get the reaction force $R_{A}$, depending on the rack extension $x_{I}$ (I. boundary):

$$
R_{A}=F_{g} \cdot\left(\frac{z}{l-x_{1}}\right) .
$$

However, the validity of this equation must be considered only in the first boundary of the rack ejection, i.e., for total ejection $x_{I}=0$ to $315 \mathrm{~mm}$. If the variable $x_{I}$ reaches a value of $315 \mathrm{~mm}$, the reaction $R_{B}$ disappears and the vector line of the total centre of gravity of the moving loading will be identical to the vertical axis of the friction wheel. Therefore, the normal force at the friction wheel $R_{A}$ will acquire a value equal to $F g$. Modification of the size of the reaction $R_{B}$ on the bearing $B$, depending on the ejection of the rack during the contact of the wheel $B$ with the profile (which allows the existence of the reaction force $R_{B}$ ), can be mathematically written (see Figure 6) in the form (3):

$$
\sum M i_{A}=0, \quad \Rightarrow R_{B} \cdot\left(l-x_{1}\right)=F_{g} \cdot\left(l-z-x_{1}\right) .
$$

However, the validity of the equation (3) must be considered again only in the first boundary of ejection, i.e., for total ejection $x_{1}=0$ to $315 \mathrm{~mm}$. We get the reaction $R_{B}$ from equation (3):

$$
R_{B}=F_{g} \cdot \frac{\left(l-z-x_{1}\right)}{\left(l-x_{1}\right)}
$$

In order to be able to immediately quantify the value of the force $F$ acting on the hand crank over the entire length of the rack $x$, it is necessary to construct an equation describing the state for the second field, i.e., for the moment when the total center of gravity is located above the friction wheel up to the point of maximum extension $x_{2}=0$ to $600 \mathrm{~mm}$.

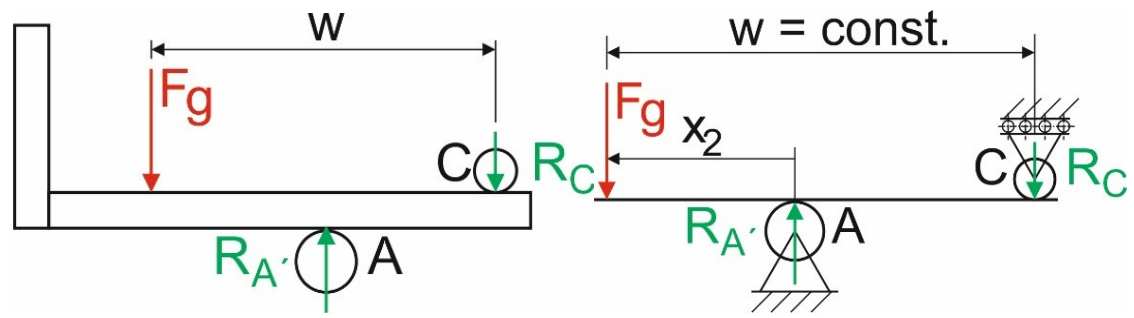

Fig. 7. Schematically depicted geometry of the pull-out position of the rack (left) and schematic representation of the rack considered as a plain beam (right)

From Fig. 7 we get the reaction $R_{A}$, (4): 


$$
\sum M i_{C}=0, \quad \Rightarrow R_{A^{\prime}} \cdot\left(w-x_{2}\right)=F_{g} \cdot w .
$$

From the equation (4) we get the reaction force $R_{A^{\prime}}$ depending on the rack ejection $x$ in the second boundary:

$$
R_{A^{\prime}}=F_{g} \cdot\left(\frac{w}{w-x_{2}}\right)
$$

However, we need only consider the validity of this equation (4) in the second boundary of ejection, i.e., for total ejection $x_{2}=0$ to $600 \mathrm{~mm}$ (at $x_{2}=0 \mathrm{~mm}$ it is also $x_{1}=315 \mathrm{~mm}$ ). From Fig. 7 right we get the reaction $R_{C}(5)$ :

$$
\sum M i_{A}=0, \quad \Rightarrow F_{g} \cdot x_{2}=R_{C} \cdot\left(w-x_{2}\right) .
$$

From the equation (5) we get the required reaction force $R_{C}$, depending on the rack ejection $x_{2}$ (II. boundary):

$$
R_{C}=F_{g} \cdot\left(\frac{x_{2}}{w-x_{2}}\right) .
$$

Analytical calculation of reactions $R_{A}, R_{B}, R_{C}$ and $R_{A^{\prime}}$ for selected boundary conditions $x_{1}=0$ and $315 \mathrm{~mm}, x_{2}=0$ and $600 \mathrm{~mm}, z=643 \mathrm{~mm}, w=1,517 \mathrm{~mm}$ :

$$
\begin{gathered}
R_{A\left(x_{1}=0\right)}=F_{g} \cdot\left(\frac{z}{l-x_{1}}\right)=5217 \cdot\left(\frac{643}{958-0}\right)=3501.5 \mathrm{~N} \\
R_{A\left(x_{1}=315\right)}=F_{g} \cdot\left(\frac{z}{l-x_{1}}\right)=5217 \cdot\left(\frac{643}{958-315}\right)=5217 \mathrm{~N} \\
R_{B\left(x_{1}=0\right)}=F_{g} \cdot\left(\frac{l-z-x_{1}}{l-x_{1}}\right)=5217 \cdot\left(\frac{958-643-0}{958-0}\right)=1715.5 \mathrm{~N} \\
R_{B\left(x_{1}=315\right)}=F_{g} \cdot\left(\frac{l-z-x_{1}}{l-x_{1}}\right)=5217 \cdot\left(\frac{958-643-315}{958-315}\right)=0 \mathrm{~N} \\
R_{C(x 2=0)}=F_{g} \cdot\left(\frac{x_{2}}{w-x_{2}}\right)=5217 \cdot\left(\frac{0}{1517-0}\right)=0 \mathrm{~N} \\
R_{C(x 2=600)}=F_{g} \cdot\left(\frac{x_{2}}{w-x_{2}}\right)=5217 \cdot\left(\frac{600}{1517-600}\right)=3413.5 \mathrm{~N} \\
R_{A^{\prime}(x 2=0)}=F_{g} \cdot\left(\frac{w}{w-x_{2}}\right)=5217 \cdot\left(\frac{1517}{1517-0}\right)=5217 \mathrm{~N}
\end{gathered}
$$




$$
R_{A^{\prime}(x 2=600)}=F_{g} \cdot\left(\frac{w}{w-x_{2}}\right)=5217 \cdot\left(\frac{1517}{1517-600}\right)=8630.5 \mathrm{~N}
$$

An analytical calculation of the reactions shows that the largest load on the rack occurs when that is maximally rejected. This maximum load also served as an input for the strength analysis of the rack system steel structure [21]. To compute the equation that explains the relation between the position of the rack $x$ and the instantaneous force $F$ on the hand crank, it is necessary to continue the calculation of the rack system transmission mechanism, the design of which will depend on the physical possibilities of the drive, i.e. human drive. The friction force $F_{T}$, between the friction wheel and the moving part of the rack, depends on the variable character of the normal force $R_{A}$ in the first boundary. We can write (6):

$$
F_{T_{-} I\left(x_{1}\right)}=R_{A\left(x_{1}\right)} \cdot \frac{\xi_{1}}{d_{K}}
$$

The rolling resistance coefficient $\xi_{l}$, depending on the type of material to be contacted (steel with steel at the $f=0.1$ (-) friction coefficient considered) and the diameter of the friction wheel $d_{K}=80 \mathrm{~mm}$, acquires the value $\xi_{l}=0.5 \mathrm{~mm}$. By applying the relation (2) to the relation (6) we get $[22,23]$ :

$$
F_{T_{-} I\left(x_{1}\right)}=F_{g} \cdot\left(\frac{z}{l-x_{1}}\right) \cdot \frac{\xi_{1}}{d_{K}}
$$

For the friction force $F_{T}$ between the friction wheel and the movable part of the rack depending on the variable character of the normal force $R_{A^{\prime}}$ in the second boundary can be written $(7)[22,23]$ :

$$
F_{T_{-} \mathrm{II}\left(x_{2}\right)}=R_{A^{\prime}\left(x_{2}\right)} \cdot \frac{\xi_{1}}{d_{K}}
$$

The geometry of the construction does not change in the second boundary, so for calculating the friction force in the second boundary, we use the same values of the rolling resistance coefficient $\xi_{1}$ and the diameter of the friction wheel $d_{K}$. By applying the relation (4) to the relation (7) we get:

$$
F_{T_{-} I I\left(x_{2}\right)}=F_{g} \cdot\left(\frac{w}{w-x_{2}}\right) \cdot \frac{\xi_{1}}{d_{K}}
$$

In addition, the rolling without slipping condition (8) must be checked to ensure that the friction wheel is not slipping on the rack.

$$
d_{K} \geq \frac{\xi_{1}}{f}
$$

By substituting the values into the relation (8) we find out that the rolling condition is fulfilled, i.e., no slip occurs between the friction wheel and the pull-out part of the rack. Then the value of the variable tensile force in bearing $B$ in the first boundary is determined (9): 


$$
F_{B T_{-} I\left(x_{1}\right)}=R_{B\left(x_{1}\right)} \cdot \frac{\xi_{2}}{r_{L}}
$$

The rolling resistance coefficient $\xi_{2}$, depending on the type of material to be contacted (steel with steel at $\mathrm{f}=0.095(-)$ and heat treatment - bearing hardening) and the radius of the ball bearing used $r_{L}=31 \mathrm{~mm}$ acquires a value of $\xi_{2}=0.005 \mathrm{~mm}$. Applying the relation (5) to the relation (9) we get:

$$
F_{B T_{-} I\left(x_{1}\right)}=F_{g} \cdot \frac{\left(l-z-x_{1}\right)}{\left(l-x_{1}\right)} \cdot \frac{\xi_{2}}{r_{L}}
$$

A similar relation also applies to the variable tensile force in bearing $C(10)$ in the second boundary:

$$
F_{C T_{-} I I\left(x_{2}\right)}=R_{C\left(x_{2}\right)} \cdot \frac{\xi_{2}}{r_{L}}
$$

Applying the relation (5) to the relation (10) we get:

$$
F_{C T_{-} I I\left(x_{2}\right)}=F_{g} \cdot\left(\frac{x_{2}}{w-x_{2}}\right) \cdot \frac{\xi_{2}}{r_{L}}
$$

The total force required to eject the pull-in rack (boundary condition: I. boundary $x_{1}=0$ $\mathrm{mm}$ ) considering the efficiency of the friction wheel mounting $\eta=0.96(-)$ is (11):

$$
F_{\text {total }\left(x_{1}\right)}=F_{B T_{-} I\left(x_{1}\right)}+\frac{F_{T_{-} I\left(x_{1}\right)}}{\eta}
$$

However, the calculated load is only one-sixth of the total value (because of the $1 / 6$ model), so it is necessary to obtain the total force required to eject the rack by multiplying the force by the constant $6(-)$. By adjusting the equation (11) for the force required to move the rack in the first boundary ( 0 to $315 \mathrm{~mm}$ ) we get:

$$
F_{\text {total }\left(x_{1}\right)}=6 \cdot F_{g} \cdot\left[\frac{\left(l-z-x_{1}\right)}{\left(l-x_{1}\right)} \cdot \frac{\xi_{2}}{r_{L}}+\left(\frac{z}{l-x_{1}}\right) \cdot \frac{\xi_{1}}{d_{K} \cdot \eta}\right]
$$

The total force required to pull in the ejected rack (boundary condition: II. boundary $x_{2}=600 \mathrm{~mm}$ ), considering the efficiency of the friction wheel mounting $\eta=0.96(-)$ is (12):

$$
F_{\text {total }\left(x_{2}\right)}=F_{C T_{-} I I\left(x_{2}\right)}+\frac{F_{T_{-} I I\left(x_{2}\right)}}{\eta}
$$

The calculated load is again only one-sixth of the total value (since the 1/6 model was used), so it is necessary to obtain the total force required to pull in the rack by multiplying the force by the constant 6 (-). By adjusting the equation (12) for the force required to move the rack in the second boundary (315 to $915 \mathrm{~mm}$ ) we get: 


$$
F_{\text {total }\left(x_{2}\right)}=6 \cdot F_{g} \cdot\left[\frac{\left(x_{2}\right)}{\left(w-x_{2}\right)} \cdot \frac{\xi_{2}}{r_{L}}+\left(\frac{w}{w-x_{2}}\right) \cdot \frac{\xi_{1}}{d_{K} \cdot \eta}\right]
$$

For maximum force, i.e., at boundary condition $x_{2}=600 \mathrm{~mm}$ we get:

$$
F_{\text {total }\left(x_{2}=600\right)}=6 \cdot 5217 \cdot\left[\left(\frac{600}{1517-600}\right) \cdot \frac{0.005}{31}+\left(\frac{1517}{1517-600}\right) \cdot \frac{0.5}{80 \cdot 0.96}\right]=340.5 \mathrm{~N}
$$

The value of this force $340.5 \mathrm{~N}$ is greater than the desired value to maintain comfortable handling of the machine by the manual force of the worker with a power of $75 \mathrm{~W}$ for crank force, i.e., $100 \mathrm{~N}$. In order the hand crank not to be too long (and thus the increase in the circumferential speed of the crank radius), the gear will be equipped with a 1:2 sprocket to slow the transmission and increase the force (see Fig. 3 in [13]). The sprocket dimensions were chosen as: the radius of the small sprocket $r_{m}=30 \mathrm{~mm}$ and $r_{v}=60 \mathrm{~mm}$. The circumferential force on a large sprocket must be with the overall friction force reduced to the friction wheel radius in balance, of course, while respecting the effectiveness of the individual kinematic pairs. The circumferential force $F_{c f_{-} I}$ on a large sprocket in the first boundary will be (13):

$$
F_{c f_{-} I\left(x_{1}\right)}=\frac{F_{\text {total }\left(x_{1}\right)} \cdot r_{K}}{r_{v} \cdot \eta_{R}}
$$

The circumferential force $F_{c f_{-} I}$ on a large sprocket in the second boundary will be (14):

$$
F_{c f_{-} I I\left(x_{2}\right)}=\frac{F_{t o t a l\left(x_{2}\right)} \cdot r_{K}}{r_{v} \cdot \eta_{R}}
$$

By applying the equation (11) into equation (13) and its adjusting we get:

$$
F_{c f_{-} I\left(x_{1}\right)}=6 \cdot F_{g} \cdot\left\{\left[\frac{\left(l-z-x_{1}\right)}{\left(l-x_{1}\right)} \cdot \frac{\xi_{2}}{r_{L}}+\left(\frac{z}{l-x_{1}}\right) \cdot \frac{\xi_{1}}{d_{K} \cdot \eta}\right] \cdot\left(\frac{r_{K}}{r_{v} \cdot \eta_{R}}\right)\right\}
$$

By applying the equation (12) into equation (14) and its adjusting we get:

$$
F_{c f_{-} I I\left(x_{2}\right)}=6 \cdot F_{g} \cdot\left\{\left[\frac{x_{2}}{\left(w-x_{2}\right)} \cdot \frac{\xi_{2}}{r_{L}}+\left(\frac{w}{w-x_{2}}\right) \cdot \frac{\xi_{1}}{d_{K} \cdot \eta}\right] \cdot\left(\frac{r_{K}}{r_{v} \cdot \eta_{R}}\right)\right\}
$$

From the balance condition on a small sprocket and crank while respecting the effectiveness of individual kinematic pairs, we get the $F_{I}$ force on the crank needed to move the rack in the first boundary at a maximum load of 3 tons (15):

$$
F_{c f_{-} I\left(x_{1}\right)} \cdot r_{m}=F_{I} \cdot R \cdot \eta_{R}
$$

A similar equation applies to the second boundary (16):

$$
F_{c f_{-} I I\left(x_{2}\right)} \cdot r_{m}=F_{I I} \cdot R \cdot \eta_{R}
$$

By putting the relation (13) into (15) we get: 


$$
F_{I}=6 \cdot F_{g} \cdot\left\{\left[\frac{\left(l-z-x_{1}\right)}{\left(l-x_{1}\right)} \cdot \frac{\xi_{2}}{r_{L}}+\left(\frac{z}{l-x_{1}}\right) \cdot \frac{\xi_{1}}{d_{K} \cdot \eta}\right] \cdot\left(\frac{r_{K}}{r_{v} \cdot \eta_{R}}\right) \cdot\left(\frac{r_{m}}{R \cdot \eta_{R}}\right)\right\}
$$

By putting the relation (14) into (16) we get:

$$
F_{I I}=6 \cdot F_{g} \cdot\left\{\left[\frac{x_{2}}{\left(w-x_{2}\right)} \cdot \frac{\xi_{2}}{r_{L}}+\left(\frac{w}{w-x_{2}}\right) \cdot \frac{\xi_{1}}{d_{K} \cdot \eta}\right] \cdot\left(\frac{r_{K}}{r_{v} \cdot \eta_{R}}\right) \cdot\left(\frac{r_{m}}{R \cdot \eta_{R}}\right)\right\}
$$

Let us substitute for the constants in these relations and we get the force on the crank in the first boundary:

$$
F_{I}=\Delta \cdot\left[\psi \cdot\left(\frac{l-z-x_{1}}{l-x_{1}}\right)+\varepsilon\left(\frac{z}{l-x_{1}}\right)\right]
$$

Force on the crank in the second boundary:

$$
F_{I I}=\Delta \cdot\left[\psi \cdot\left(\frac{x_{2}}{w-x_{2}}\right)+\varepsilon\left(\frac{w}{w-x_{2}}\right)\right]
$$

$\Delta$ is defined as the geometric constant of the structure and its value is $\Delta=0.4527(-) . \psi$ is the weight constant of the moving part of the load-free rack and its value does not depend on the load weight $-\psi=0.84145 \mathrm{~N}$. $\varepsilon$ is the load constant at load with a mass of $3,000 \mathrm{~kg}$ and in this case $\varepsilon=33.951 \mathrm{~N}$. Meaning and dimensions of other marks in crank force relations: $l=958 \mathrm{~mm}, z=643 \mathrm{~mm}, w=1,517 \mathrm{~mm}$. Sample analytical calculation of crank force for extreme positions $\left(x_{1}=0 \mathrm{~mm}, x_{2}=600 \mathrm{~mm}\right)$ :

$$
\begin{gathered}
F_{I\left(x_{1}=0\right)}=0.4527 \cdot\left[0.84145 \cdot\left(\frac{958-643-0}{958-0}\right)+33.951 \cdot\left(\frac{643}{958-0}\right)\right]=10.465 \mathrm{~N} \\
F_{I I\left(x_{2}=600\right)}=0.4527 \cdot\left[0.84145 \cdot\left(\frac{600}{1517-600}\right)+33.951 \cdot\left(\frac{1517}{1517-600}\right)\right]=25.67 \mathrm{~N}
\end{gathered}
$$

The crank force distribution is drawn using the Matlab program [24], depending on the position of the rack, i.e., position in the first or second field (Fig. 8).

In Fig. 8, there is a graphical representation of the variable force $F$ acting on the hand crank depending on the rack extension $x$. The red line (dash-dotted) depicts the force on the crank according to the modified $F_{I}$ equation. It is necessary to realize that the equation applies only to the first boundary, i.e. when the bearing $B$ is in contact (in Fig. 8 the red line is highlighted in green-thick line). For the calculation of the force $F$, which actually acts on the crank in the second boundary of rack ejection, a modified final equation for the $F_{I I}$ has to be entered into the Matlab program. This equation only applies in the second boundary, i.e., when the bearing $C$ is in contact (in blue - dashed line, the blue colour is highlighted thick in Fig. 8). 


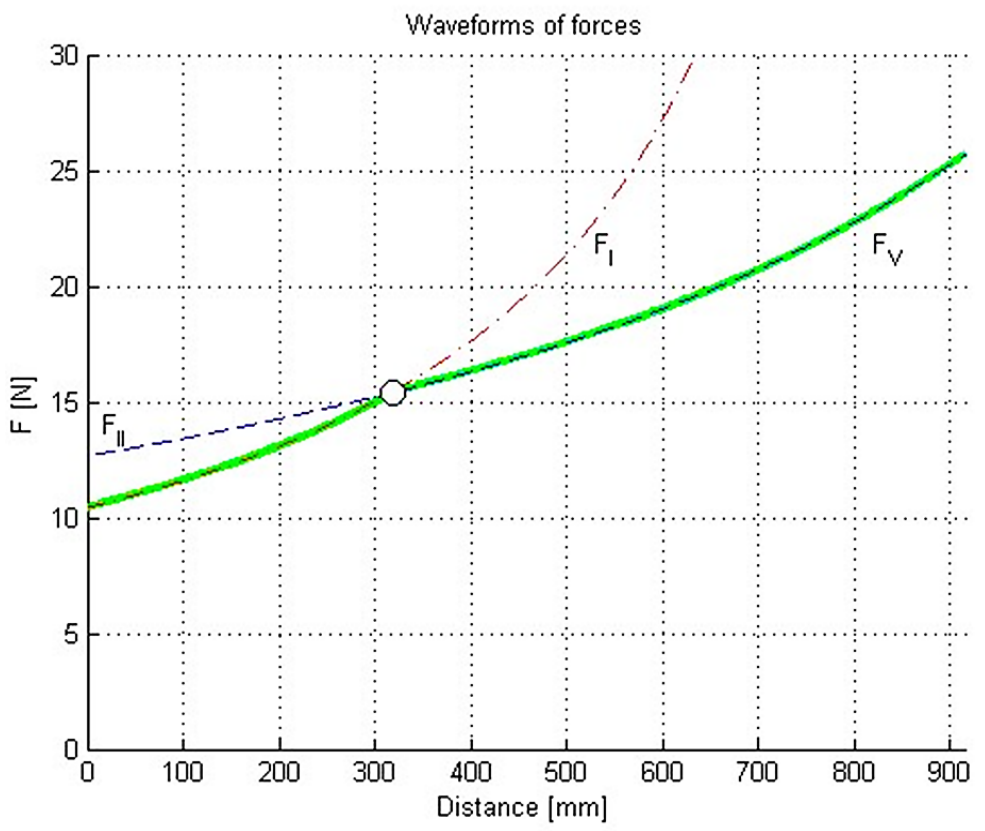

Fig. 8. Graphic representation of the force size $\mathrm{F}$ acting on the hand crank depending on the rack extension $\mathrm{x}$ when the machine dynamics influence is neglected

The further research of the designed rack system will be focused on setting-up multibody system for investigation of dynamic properties of the rack system [25-27]. In the next step, the prepared FEM will be used for importing to the MBS model to create flexible MBS system [28, 29]. Such a model will serve for more detailed analysing of dynamic effects on the structure.

\section{Conclusion}

In the paper, a strength reanalysis of a tree rack system designed for an engineering company warehouse is performed due to exceeding the permissible stresses in the original design. In the mechanism operation, it has been found that the optimized structure withstands the load, but the necessary force effect applied on the hand crank of this mechanism is variable depending on the size of the rack extension. Therefore, the paper describes the methodology for determining the instantaneous value of crank force and the creation of the equation. That, as we assume, will serve as an input for the creation and calculation of the motion differential equation of the mechanism with the dynamic influence assumed. This, at the functional analytical calculation, did not happen due to the small working speeds and acceleration of the machine, resulting from a source of power of a person who uses their own physical force corresponding to the permanent output of the average person, which is $75 \mathrm{~W}$. The next step in solving this issue will be verification of the complexity and usability of the structure in creating additional innovated rack systems.

The work was supported by the Cultural and Educational Grant Agency of the Ministry of Education of the Slovak Republic in project No. KEGA 077ŽU-4/2017: Modernization of the Vehicles and engines study program.

This publication is the result of the project implementation: Modern methods of teaching control and diagnostic systems of engine vehicles ITMS 26110230107 supported by the Operational Programme Education funded by the ESF. 


\section{References}

1. P. Drozdziel, K. Wawer, R. Madlenak, M.O. Mussabekov, Concepts of load handling devices, adjusted do light goods vehicles of the weight up to $3.5 \mathrm{t}$. Communications Scientific Letters of the University of Žilina 19, 96-102 (2017)

2. A. Zrak, J. Mesko, J. Moravec, R. Nigrovic, D. Kadas, Contactless thermal bending of steel sheets. Manufacturing Technology 16, 309-313 (2016)

3. J. Moravec, Increase of the operating life of active parts of cold-moulding tools. Tehnicki vjesnik-technical Gazette 24, 143-146 (2017)

4. J. Moravec, Magnetic field application in area sheet metal forming. $25^{\text {th }}$ Anniversary International Conference on Metallurgy and Materials METAL 2016 25, 303-309 (2016)

5. J. Gallikova, R. Poprocky, P. Volna, Implementation of FMEA method in maintenance of semi-trailer combination. Diagnostyka, 17, 85-92 (2016)

6. J. Gallikova, V. Stuchly, R. Poprocky, P. Volna, Model calculation of posterior reliability indicators for the proposal of the maintenance system. MATEC Web of Conferences, 157 (2018)

7. P. Kopas, M. Saga, F. Novy, B. Leitner, Low-cycle fatigue behaviour of lase welded high-strenght steel DOMEX 700 MC. MATEC Web of Conferences, 157 (2018)

8. J. Bajla, J. Broncek, J. Antala, D. Sekeresova, Mechanical Engineering Tables. Selection Standards. (In Slovak). (Slovak Office of Standards, Metrology and Testing, 2014)

9. M. Handrik, M. Vasko, P. Kopas, M. Saga. Effective finite element solution and postprocessing for wide load spectrum. Communications - Scientific letters of the University of Zilina 16, 19-26 (2014)

10. P. Kopas, M. Saga, V. Baniari, M. Vasko, M. Handrik, A plastic strain and stress analysis of bending and torsion fatigue specimens in the low-cycle fatigue region using the finite element methods. Procedia Engineering 177, 526-531 (2017)

11. Rudawska, I. Miturska, J. Szabelski, A. Skoczylas, P. Drozdziel, E. Bociąga, R. Madlenak, D. Kasperek, Experimental research and statistic analysis of polymer composite adhesive joints strength. Journal of Physics: Conference Series, 842 (2017)

12. L. Jakubovicova, B. Ftorek, V. Baniari, A. Sapietova, T. Potocek, M. Vasko, Engineering design of a test device. Procedia Engineering 177, 520-525 (2017)

13. M. Blatnicka, M., Saga, M. Blatnicky, Design and strength analysis of mechanical rack system. MATEC Web of Conferences (to be published).

14. J. Gerlici, T. Lack, J. Harusinec, Realistic simulation of railway operation on the RAILBCOT test stand. Applied Mechanics and Materials 486, 387-395 (2014)

15. L. Jakubovicova, M. Saga, M. Handrik, Numerical analysis of stiffener for hybrid drive unite. MATEC Web of Conferences, 157 (2018)

16. L. Smetanka, P. Stastniak, Analysis of contact stresses of theoretical and worn profile by using computer simulation. Manufacturing Technology 17, 580-585 (2017)

17. B. Leitner, M. Vasko, Design and modelling of tank wagon assembly operations in CAM environment. $19^{\text {th }}$ International Conference TRANSPORT MEANS 2015 19, 8790 (2015)

18. L. Smetanka, J. Gerlici, T. Lack, Z. Pelagic, Homogenization of fibers reinforced composite materials for simulation analysis. Manufacturing Technology 15, 914-920 (2015) 
19. B. Skocilasova, J. Skocilas, J. Soukup, Forced convection and heat transfer around a bounded cylinder. MATEC Web of Conferences, 157 (2018)

20. I. Hren, P. Hejma, S. Michna, M. Svoboda, J. Soukup, Analysis of torque mechanism. MATEC Web of Conferences, 157 (2018)

21. A. Sapietova, M. Saga, A. Shimanovsky, M. Sapieta, Mobility of multibody systems in terms of their incorrectness. Communications - Scientific letters of the University of Zilina 16, 6-12 (2014)

22. J. Gerlici, T. Lack, J. Harusinec, Test stand properties analysis for wheels tread wear in accordance to the laboratory simulated railway operation. $13^{\text {th }}$ Mini Conference on Vehicle System dynamics, Identification and Anomalies, VSDIA 2012 13, 157-165 (2012)

23. A. Suchanek, J. Harusinec, M. Loulova, P. Strazovec, Analysis of the distribution of temperature fields in the braked railway wheel. MATEC Web of Conferences 157 (2018)

24. J. Gerlici, T. Lack, Iterative method railway wheel profile design. Komunikacie 11, 4956 (2009)

25. V. Hauser, O. Nozhenko, K. Kravchenko, M. Loulova, J. Gerlici, T. Lack, Proposal of a mechanism for setting bogie wheelset to radial position while riding along track curve. Manufacturing Technology 17, 186-162 (2017)

26. V. Hauser, O. Nozhenko, K. Kravchenko, M. Loulova, J. Gerlici, T. Lack, Car body and bogie connection modification for track curves passability improvement. MATEC Web of Conferences, 157 (2018)

27. T. Lack, J. Gerlici, Wheel/rail tangential contact stress evaluation by means of the modified strip method. Communication - Scientific Letters of the University of Zilina 16, 33-39 (2014)

28. J. Gerlici, R. Domin, G. Cherniak, T. Lack, Calculated estimation of railway wheels equivalent conicity influence on critical speed of railway passenger car. MATEC Web of Conferences, 157 (2018)

29. J. Harusinec, A. Suchanek, M. Loulova, P. Strazovec, Design of a device to simulate environmental influences of the course of brake tests. MATEC Web of Conferences, 157 (2018) 